\title{
Políticas Públicas de Juventude no Espírito Santo: experiências tecidas em um percurso profissional
}

\author{
Public Policies for Youth in the state of Espírito Santo: experiences \\ elaborate into a professional path
}

\author{
Mônica Patrícia Gomes Machado; Ana Lucia C. Heckert. \\ Universidade Federal do Espírito Santo
}

\section{RESUMO:}

Este artigo compartilha análises apresentadas em pesquisa de dissertação de mestrado que focalizou as políticas de juventude no estado do Espírito Santo. A dissertação objetivou contribuir no debate acerca dos processos de criminalização e silenciamento da juventude negra e pobre capixaba, moradora das periferias urbanas. As temáticas abordadas foram delimitadas a partir de análises acerca da vivência profissional da autora principal, atuando como psicóloga no âmbito de políticas voltadas à juventude. Delimitamos alguns eixos desta experiência profissional para debater o modo com as políticas governamentais são efetuadas, em boa parte dos casos sem uma escuta cuidadosa e analítica acerca das demandas deste segmento da população. Almejamos colocar em análise a chamada 'onda jovem' que significou o crescimento da população juvenil, o incremento à participação dos jovens na construção de políticas públicas para este segmento, assim como as ações que vêm fomentando de forma cada vez mais intensa o processo de criminalização da juventude pobre e negra.

Palavras-chave: juventude; políticas públicas; criminalização

\begin{abstract}
:
This dissertation intends to contribute to the argumentation about the processes of criminalization and silencing of the black and poor youth of the city of Espírito Santo, who lives in the suburb. The topics covered here were based on analyzes about the author's professional experience as a psychologist in the area of youth public policies. Some axes were delimited of this professional experience with the youth to discuss how government policies are carried out, in most of cases without careful and analytical listening about the demands of youth population. We aim to analyze the phenomenon 'young wave' that has meant the growth of the youth population, the increase in the participation of young people in the construction of public policies for this segment, as well as the actions that have been increasingly intense the process of criminalization of poor and black youth.
\end{abstract}

Key-words: youth; public policy; criminalization

DOI: 10.12957/mnemosine.2021.61849 


\section{Nossos percursos de pesquisa}

Este artigo é derivado de uma pesquisa para elaboração de dissertação de mestrado e objetiva contribuir no debate acerca dos processos de criminalização e silenciamento da juventude pobre capixaba, moradora das periferias urbanas. As temáticas aqui abordadas foram delimitadas a partir de análises acerca da experiência profissional como psicóloga por uma das autoras, que atuou e continua atuando no âmbito das políticas voltadas à juventude.

O desafio deste trabalho, formulado no processo de qualificação do projeto de pesquisa, foi o de extrair da trajetória profissional algumas questões concernentes ao processo de elaboração de políticas públicas de juventude. Para lidar com este desafio, daremos destaque às práticas inquietantes que nos deslocaram de lugares, ofuscaram o olhar e apontaram questões acerca das políticas de juventude.

$\mathrm{Na}$ verdade, o grande desafio foi efetuar um processo intenso de análise de implicações e de sobreimplicação. Ao chegar no mestrado a autora principal do artigo mantinha uma certa crença de que os caminhos trilhados na construção de políticas públicas governamentais de fato poderiam garantir produção de autonomia em suas vidas. Acreditava que criar mecanismos de escuta dos jovens e de espaços de participação na formulação das políticas governamentais iria viabilizar que interferissem nos rumos dessas políticas.

Lourau (2004a) aponta que a implicação é um nó de relações que estabelecemos com as instituições, aqui entendidas como práticas sociais historicamente produzidas e que vivem um processo de naturalização desta mesma constituição. Não há neutralidade, tampouco é possível alcançar o ideal de uma suposta objetividade que garantiria fidedignidade aos saberes produzidos. Como afirmava Lourau (2004a: 147-148): "Estar implicado (realizar ou aceitar a análise de minhas próprias implicações) é, ao fim de tudo, admitir que eu sou objetivado por aquilo que pretendo objetivar; fenômenos, acontecimentos, grupos, idéias, etc.” Este autor nos advertiu ainda que o mais importante não é constatar as nossas implicações, mas analisá-las, a fim de desmontar certas práticas que reificamos em nossas vidas cotidianas. As implicações estão vinculadas às relações de poder, aos lugares que ocupamos nas relações de saber-poder, os valores morais que alimentamos, dentre outros, como aponta Coimbra (1995: 66):

[...] a Análise Institucional vai nos falar do intelectual implicado, definido como aquele que analisa as implicações de suas pertenças e referências institucionais, analisando, também, o lugar que ocupa na divisão social do trabalho, da qual é legitimador. 
Portanto, analisa-se o lugar que se ocupa nas relações sociais em geral e não apenas no âmbito da intervenção que está sendo realizada; os diferentes lugares que se ocupa no cotidiano e em outros locais da vida profissional; em suma, na história.

Analisar nossas implicações requer chacoalhar muitos valores morais, verdades, práticas sociais em que fomos forjadas como sujeitas. Neste caso, entrava em cena as implicações que estabelecia com este grupo social chamado juventude, com o lugar de psicóloga ocupando um cargo na máquina estatal para implementar políticas governamentais, com os dispositivos formais de participação social, com nosso mandato social como psicóloga, dentre outras. Esta análise de implicações interferia na pesquisa que realizava, não apenas fazendo delineamentos das questões que seriam debatidas, como principalmente produzindo silenciamentos, e efetuando bifurcações e problematizando os pertencimentos que atravessavam meu fazer profissional.

É também Lourau (2004b) quem vai nos advertir acerca dos usos que a noção de implicação acabou lidando, compondo atualmente um viés voluntarista que exalta as implicações do trabalhador, do pesquisador, do estudante, enaltecendo o sobretrabalho cada vez mais mal remunerado. $\mathrm{O}$ enaltecimento à dedicação do trabalhador, à participação do cidadão na construção de políticas públicas, à lealdade ao partido e o engajamento na comunidade, ao ativismo que busca tudo resolver, podem favorecer o esvaziamento político dos debates coletivos desses lugares que ocupamos (COIMBRA; NASCIMENTO, 2004). Analisar nossas implicações/sobreimplicações envolve, necessariamente, desnaturalizar as práticas sociais que alimentamos e ampliar os graus de transversalidade de dada situação que vivenciamos.

A metodologia que usamos nesta pesquisa partia de minha própria trajetória de trabalho. A convocação e provocação da banca era de que usasse como matéria prima da pesquisa as experiências que efetuei no processo de construção de algumas políticas de juventude no Espírito Santo. Na verdade o campo da pesquisa era minha própria experiência. Este processo colocava em cena a necessária problematização de um percurso profissional, e isso não se faz sem deslocamentos, incômodos, inflexões e conflitos. Não foi fácil perceber certos viéses que atravessaram essa trajetória, como a compreensão de que pela via da conscientização dos técnicos e dos próprios jovens, seria possível fortalecer a produção de políticas públicas participativas.

O nó de relações deste percurso profissional trouxe a importância de analisar implicações, ficar atenta às relações de poder e saber que engendraram políticas e ações nas quais estive envolvida. Afinal, era de uma experiência profissional que se tratava. A 
experiência é aquilo que nos passa, nos atravessa e na qual nos tornamos outros (LARROSA, 2011). Trazer uma experiência como matéria prima de uma pesquisa acadêmica é sempre tratar de deslocamentos, desvios, derrapadas, zonas de não saber, repetições de práticas naturalizadas, atrevimentos e impasses.

Porque a abertura que a experiência dá é a abertura do possivel, mas também do impossível, do surpreendente, do que não pode ser. Por isso a experiência sempre supõe uma aposta pelo que não se sabe, pelo que não se pode, pelo que não se quer. A experiência é um talvez. Ou, o que é o mesmo, a experiência é livre, é o lugar da liberdade" (LARROSA, 2011: p.19)

A construção dessas análises se deu a partir de um longo processo de reencontro com experiências profissionais que atravessaram a minha vida, me conduzindo para lutas e militâncias num campo que vinha sendo pautado no país - a juventude. Tomar esse reencontro como o campo de pesquisa me levou a encontros e indagações com práticas de trabalho, modos de pensar a juventude e de fazer gestão de políticas públicas que se pautavam em certezas, tais como: "tínhamos encontrado o lugar para juventude", "tínhamos dado voz" à juventude e às suas expressões, estávamos alcançando o "grande sonho" de construção de políticas públicas para juventude.

Tomar meu percurso profissional e de militância como empiria da pesquisa me fez desconstruir espaços antes seguros. O grande sonho da participação popular, via políticas estatais, foi atravessado por tantas outras linhas que me tiraram do lugar seguro, me fizeram colocar em questão minhas práticas profissionais, meus debates e a minha militância.

E não podemos deixar de ressaltar que mesmo em meio a tantos controles e regulamentação da vida, a construção de políticas governamentais voltadas à juventude foi efeito de lutas necessárias e fundamentais, em um país que banaliza a morte de jovens negros e pobres.

Partimos de experiências tecidas em um percurso profissional para debater questões, indagações, análises acerca das políticas públicas direcionadas à juventude, buscando colocar em análise o incremento à participação em tais políticas, assim como as ações que vêm fomentando de forma cada vez mais intensa o processo de criminalização da juventude pobre e negra. Para isso o estudo iniciou tomando como caminho a trajetória de vida profissional, as práticas como trabalhadora em políticas públicas de juventude, os desafios, a gestão da políticas públicas, as “formulações” dessas políticas, dentre outros tantos elementos vividos. Atuando nessas políticas foi possível 
perceber que o modo de organização de algumas políticas estatais, bem como a ação de seus trabalhadores, podem estar fortalecendo o controle dessas vidas, pautados em crenças de que somente alguns caminhos sejam possíveis, quais sejam: o jovem ser inserido no mundo trabalho, se manter na escola, se "proteger" contra o uso de drogas e de uma possível captura pelo tráfico, constituir uma família futuramente...

Mas será que não estamos falando de modelos hegemônicos? Que formas de vida podemos pensar para além do que se apresenta como "bom para jovem", como um "bemestar" e que responde a uma demanda do modo de produção capitalista para alguns grupos sociais? Nosso intuito foi colocar em análise a convocação da juventude para ocupar determinados espaços de construção das políticas públicas, assim como os efeitos dos formatos dados por essas políticas na vida do jovem pobre da periferia. Lidamos com políticas que se propõem a dar soluções e respostas para um determinado grupo social, por isso consideramos necessário debater as consequências da entrada dessas políticas na vida dos jovens.

Para definir quais dos percursos profissionais trilhados seriam utilizados como campo de pesquisa da dissertação, fizemos inicialmente um relato das inserções efetuadas que estavam vinculadas à questão da juventude, uma vez que este era o nosso foco de trabalho. Posteriormente, tomamos estes relatos e demarcamos aquelas experiências que poderiam ser tomadas como analisadoras das práticas de gestão das políticas públicas voltadas à juventude pobre, em sua maioria negra. Na sequência procurei documentos acerca das conferências municipais e estadual, consultei colegas com os quais atuei neste percurso profissional, reli anotações e registros feitos, também pesquisei sites na busca do relatório final da conferência estadual de juventude realizada em 2008, mas nada foi localizado. Com esse material em mãos definimos os eixos que iriam compor as análises deste percurso profissional, tendo como foco as ações efetuadas nas políticas de juventude.

Assim, na dissertação intitulada 'Políticas Públicas de Juventude no Espírito Santo: experiências tecidas em um percurso profissional', debatemos os processos de participação da juventude em um dispositivo formal de participação, que foi a conferência estadual de juventude, e a criminalização dos jovens pobres de periferia, por meio de programas sociais em conexão com políticas de segurança pública, reafirmando o mito da periculosidade dos jovens pobres. Neste artigo partilharemos as experiências de participação da juventude na Conferência Estadual de Juventude realizada em 2008. 


\section{A juventude como problema e perigo}

Antes de apresentar o percurso efetuado nas políticas governamentais destinadas à juventude, queremos brevemente debater algo que se tornou evidente ao colocar em análise este percurso profissional, a saber: a juventude como problema biopolítico. Pois, foi no processo de formação ocorrido no Mestrado e as leituras de vários autores como Foucault (1996 e 1999), Cecília Coimbra e Maria Livia Nascimento (2005), Denise Cordeiro e Estela Scheinvar (2007), Ricardo Miguel (2014), Sposito e Carrano (2003), que me fizeram perceber como a juventude se tornou objeto de preocupação para as políticas governamentais.

Mas não podemos deixar de registrar que a juventude como um perigo, um risco a ser controlado ou cuidado, é um processo que não se inicia com a chamada 'onda jovem'. Este marco utilizado por alguns autores e este debate acerca da "onda jovem" está circunscrito às formulações das políticas públicas a partir dos anos 80 do século XX. Porém, não esgota e nem encerra os debates acerca dos processos de participação da juventude, tampouco a relação entre juventude e políticas públicas, menos ainda acerca das políticas estatais direcionadas a este grupo social. A juventude nos anos 60 e 70 já havia expressado formas de resistência que indagavam as práticas instituídas na vida cotidiana. Os movimentos libertários dos anos 60, no Brasil e em nível mundial, sejam aqueles que indagavam o racismo, o machismo e os modos de vida hegemônicos, sejam aqueles que atacavam questões relativas ao modelo econômico vigente nos anos 60 e 70, já questionavam acerca do lugar da juventude e suas condições de vida.

Cabe também mencionar que não consideramos pertinente afirmar que foi a partir do final do século XX e início do século XXI que a juventude se tornou alvo de políticas públicas. Produções como as de Coimbra e Nascimento (2005) apontam que o jovem pobre é caracterizado como criminoso, perigoso e não humano, sendo alvo de políticas de segurança pública, de políticas de controle e de tutela. Teorias racistas e eugenistas do século XIX, segundo as autoras, contribuíram para fixar os pobres, e sobretudo os pobres negros, no lugar do risco, do perigo. As crianças e os jovens supostamente em perigo deveriam ser vigiados e controlados ao nível das virtualidades para que não se tornassem maus pobres. Muitas políticas estatais foram criadas visando controlar e disciplinarizar crianças e jovens, contribuindo para produzir juventudes desiguais, enclausurando a infância e a juventude em abrigos ou prisões, com a justificativa de protegê-las.

As políticas estatais voltadas aos jovens pobres, com alguns eixos de preocupação 
que incidiam sobretudo na educação e no trabalho, começaram a ser esboçadas na década de 2000, como afirmam Sposito e Carrano (2003). Mas como o jovem passou a ser centro dessas ações? Antes desse momento não se tinha notícia de secretarias voltadas especificamente para a juventude, as políticas para o público jovem estavam inseridas em outras políticas. Já a partir dos anos 2000 passamos a conviver com políticas governamentais com foco direcionado nesse público, ou seja, passam a ser "alvo" de um interesse específico.

A dinâmica populacional do contingente jovem reflete processos que vêm ocorrendo, particularmente nas três últimas décadas, e afetando a estrutura etária da população brasileira. Estes são a queda da fecundidade e da mortalidade. Assim a desaceleração no ritmo de crescimento da população de 15 a 24 anos é consequência da intensa e continuada queda da fecundidade. Seus efeitos - como ondas sucessivas - vão se fazer sentir nas faixas etárias subsequentes a cada década. O impacto desse processo resulta num aumento absoluto da população que vai engrossando as faixas etárias seguintes fenômeno caracterizado como onda jovem (Madeira e Bercovich, 1992) - tanto pela queda da fecundidade quanto pelo decréscimo da mortalidade infantil. (OLIVEIRA, 1998: 08)

O processo nomeado como "onda jovem" apontou para um crescimento excepcional da população jovem, um boom de pessoas na faixa etária entre 15 e 24 anos que os estudos estatísticos começaram a identificar na década de 90 (MIGUEL, 2014: 51). O ápice deste crescimento populacional se deu em 2008, quando a população de jovens no Brasil chegou a 51,3 milhões de pessoas, de acordo com dados do Instituto de Pesquisa Econômica Aplicada (IPEA, 2013). Porém, este mesmo estudo do IPEA salienta que esta população atingiu de forma relativa o pico de seu crescimento em 1983.

Sposito e Carrano (2003) indicam que o foco em construção de políticas públicas voltadas aos jovens surgiu no momento em que já ocorria a “onda jovem”. Período em que as desigualdades sociais se tornavam cada vez mais preocupantes, expondo uma política estatal frágil no que se refere a lidar com os efeitos destas desigualdades. Mas, não podemos deixar de ressaltar que este fenômeno intitulado "onda jovem" diz respeito a um processo demográfico que impactaria de alguma forma as políticas públicas. E ainda, que a intensificação das desigualdades sociais no final dos anos 80 e 90 se efetuava em função de um neoliberalismo que já mostrava seus sinais aqui no Brasil.

Em nosso país, a partir de meados dos anos 1980, com a gradativa implantação de medidas neoliberais - onde a nova ordem mundial começa a aparecer com seus corolários de globalização do mercado, Estado Mínimo, flexibilização do trabalho, desestatização da economia, competitividade, livre comércio e privatização - temos uma massiva produção de insegurança, medo, pânico articulados ao crescimento do desemprego, da exclusão, da pobreza e da miséria. Nesse dantesco quadro, os jovens pobres, quando escapam do extermínio, são os "excluidos por excelência", pois sequer 
conseguem chegar ao mercado de trabalho formal. Sua atuação em redes ilegais como o circuito do narcotráfico, do crime organizado, dos sequestros, dentre outros vem sendo tecida como única forma de sobrevivência e se prolifera, cada vez mais, como práticas de trabalho à medida que aumenta a apartação social. (COIMBRA; NASCIMENTO, 2005: 8)

No auge da "onda jovem" em tempos neoliberais, o aumento desta população significava também dificuldades de acesso aos serviços públicos, acesso à educação, qualificação para o trabalho, riscos de mortes violentas de jovens negros, dentre outros sérios problemas. Além desses jovens em sua maioria pertencerem a famílias com rendas extremamente precárias. Mas que atenção devemos ter com esses indicadores que revelam um quadro instalado no Brasil desde tempos remotos e sua relação com a precarização de políticas públicas? (MIGUEL, 2014). Devemos atentar para o modo como esses indicadores foram utilizados também como justificativa de intervenção para o controle de massas e criminalização da pobreza. A juventude, principalmente a pobre e negra, sempre sofreu com as várias tentativas de aprisionamentos e controles de suas vidas. Anteriormente categorizado como "menor", tal nomeação produzia e reforçava o lugar de desviantes, delinquentes, rebeldes, dentre outros. E quando falamos da precarização das políticas públicas, esse grupo populacional passa a estar mais exposto, por exemplo, a um sistema escolar que o classifica, funcionando como uma maquinaria a enquadrá-lo em certo modo de existir, sem considerar os efeitos de universalizar e totalizar seus modos de vida, além dos índices de violência e mortalidade que os jovens negros e pobres são alvo.

Foucault (2012) nos traz que o exercício do poder passa a se voltar não apenas para disciplinarizar os corpos dos indivíduos, mas também em um controle da população por meio de estatísticas e medições. A biopolítica inicia se ocupando da natalidade, da morbidade e das incapacidades biológicas diversas, e desse campo a biopolítica vai extrair o seu saber e definir a área de intervenção do seu poder. Nesse novo modo de exercer o poder, lida-se com um novo corpo, um corpo múltiplo, um corpo com inúmeras cabeças, um corpo numerável, mensurável. É a noção de população. A biopolítica lida com a população como um problema político. Podemos dizer que estão em cena duas tecnologias de poder (disciplinar e biopolítica) que funcionam de modos diferentes, mas que se articulam. A disciplinar centrada no corpo, com efeitos individualizantes, para o aumento da capacidade produtiva do corpo. E a biopolítica que é centrada na vida, que se volta para a população, a massa, que busca gerir os riscos e as vulnerabilidades. Sendo 
assim, os processos de fazer viver passam a conviver de maneira paradoxal com os processos de deixar morrer, de destruição, entendendo que Foucault se referia não apenas a morte física, mas a tudo que expõe a morte, que leva ao risco de morte ou a morte política, expulsão, rejeição, exclusão, etc. (FOUCAULT, 2012)

E nesse cenário de biopolítica a "onda jovem” emerge como um problema para o Estado, pois apresenta um crescimento populacional de jovens, produzindo a necessidade de se regulamentar suas vidas por meio de intervenções e controles. Foucault (2012: 132) afirma: "Este biopoder, sem a menor dúvida, foi elemento indispensável ao desenvolvimento do capitalismo". E a partir daí podemos questionar o surgimento de determinadas políticas que visam o controle de massas e não a afirmação de suas vidas e o exercício de autonomia ${ }^{2}$ dos sujeitos. Expandindo essa discussão Foucault nos mostra como se efetua a gestão de liberdade, uma perversa utilização do que se entende enquanto liberdade, pois não se trata de "ser livre", e sim de uma produção de um tipo de "liberdade", em que se cria os meios para que sejamos livres, mas sob práticas de controle, que produzem essa liberdade e a limita.

Miguel (2014) nos diz que devemos ficar atentos aos mecanismos biopolíticos de controle da população, que se efetuam por meio de uma gestão de riscos e perigos populacionais, delimitando de modo sutil certos limites "de liberdade", que incidirão sobre grupos eleitos como foco das políticas sociais. Essa "liberdade" é gerida, controlando o que coloque em xeque o seu modo de funcionamento, que seriam as tentativas de efetuar exercícios de autonomia. Estes controles biopolíticos efetuam a gestão da vida dos jovens pobres de periferia por meio da delimitação dos riscos e perigos a serem controlados, administrados e impedidos.

Neste processo o boom da "onda jovem" foi sendo visto no Brasil como um risco. O risco que nos anos 90 acirrou a crise do desemprego juvenil, com a existência de limitadas oportunidades de primeiro emprego, principalmente para os jovens pobres, e as desigualdades sociais que eram cada vez mais preocupantes. $\mathrm{O}$ aumento da população jovem significava, também, insuficiente acesso a serviços públicos, ocasionando dificuldades diversas. E, assim, o crescimento de um grupo populacional - jovens, que historicamente foi forjado como problema, justifica o controle biopolítico por parte do Estado, com construções de políticas não voltadas para um exercício da autonomia, e sim políticas revestidas de uma tutela, de uma suposta proteção da juventude.

A forma como é produzida a atenção sobre a juventude pobre amplia um olhar negativo e seletivo sobre o jovem, que sustenta essa noção de "risco", "perigo", 
"problema", “ameaça". Como apontam Bussinger e Neves (2016: 277), debatendo políticas públicas direcionadas à juventude pobre:

o caráter estrutural e histórico de desigualdade social da sociedade brasileira é refletido pelos idealizadores/coordenadores nas políticas. São marcadamente direcionadas a jovens de localidades empobrecidas com forte cunho discriminatório compreendendo necessidades de "ocupação" de uma juventude "ociosa", vítimas dos problemas sociais e, ao mesmo tempo, instrumentalizá-los para o desenvolvimento da "comunidade", fomentando um imaginário que o condiciona a uma estrutura em que, além de ser classificado, condicionado e estigmatizado, ele passa a "dever" um retorno à sociedade.

Desta forma, na noção de biopolítica, sua atuação sobre a população jovem, negra e pobre, eleita como "risco" e "problema", se faz sob a gestão de suas vidas a partir de parâmetros estatísticos que se colocam como norma para se viver. Foucault (1999) afirma que a biopolítica é exercida através de mecanismos reguladores globais, que agem na criação de estados globais de equilíbrio, como uma norma geral de vida. E, assim, tudo que escape a este suposto equilíbrio apresenta "risco" e "perigo".

$\mathrm{Na}$ tentativa de supostamente salvar o jovem que se torna objeto de ação de tais políticas, naturaliza-se a juventude como um problema, inserindo-os em programas governamentais para serem "recuperados". Não são políticas que se voltam para o jovem enquanto potência, que buscam incorporar e dialogar com os interesses dos jovens. São políticas que reforçam um enquadramento de vidas e que somente a partir de suas pedagogias prontas, irão "salvar o jovem”. Essa dita proteção está direcionada para um determinado grupo: o jovem negro, pobre, periférico. Para o cumprimento dessa proteção deve estar participando de projetos e programas que "darão conta" de alguma ocupação para suas vidas. Assim o perigo biopolítico vai sendo modulado, modelado e colocado a empreender sua vida nas cercanias das possibilidades de vida gestadas por meio de políticas estatais, que visam muito mais regulamentar os modos de vida da juventude do que expandir uma existência autônoma e potente. A criminalização dos jovens negros e pobres é uma das facetas da política de extermínio da juventude que está em curso.

Neste terreno biopolítico é que foram tecidas as experiências que vivenciei como psicóloga em serviços, programas ou ações voltadas à juventude pobre, e que na sequência partilharei. Traremos para este debate a construção da conferência estadual de juventude realizada em 2008, tendo como tema "Levante sua Bandeira".

\section{Caminhadas por entre políticas governamentais e militâncias}

Após me graduar em psicologia no Rio de Janeiro e retornar ao Espírito Santo, 
ingressei na Secretaria de Estado do Trabalho, Assistência e Desenvolvimento Social/ES (SETADES) como técnica do Programa de Erradicação do Trabalho Infantil (PETI). Neste órgão desenvolvi ações de apoio técnico à Coordenação Estadual do Programa realizando atividades de apoio burocrático nos municípios do Estado. Perto de completar 01 ano nesta função, a Secretaria passou por uma reformulação em seu organograma, seguindo os rumos nacionais na implantação da Política Nacional da Assistência Social (SUAS). Nas mudanças internas necessárias para implementar as diretrizes do SUAS, novas gerências foram criadas e também novos cargos. Nessa nova organização fui promovida à função de Coordenadora Estadual de Juventude, sendo esta minha primeira experiência como gestora em políticas de juventude. Ocupar cargos de gestão não estava entre os meus planos profissionais, sendo assim esse processo não transcorreu de forma tranquila. Essa experiência exigiu habilidades no trato com as políticas públicas, seus entraves, seus desdobramentos, suas minúcias e disputas políticas, além de lidar com imensas barreiras em diversos campos, sobretudo no campo da juventude.

As experiências efetuadas me proporcionaram o trabalho direto com os jovens em seus territórios, trazendo muitas inquietações e me provocaram a me aproximar da militância nesse campo. Com essas inquietações passei a integrar o Observatório Capixaba de Juventude, composto por militantes que tinham experiências de trabalhos com a juventude, com pesquisas e gestão de projetos, além de atuar com estudos e formações sobre juventude. Este grupo participou ativamente da I Conferência de Juventude do Espírito Santo, vivenciamos e contribuímos nesse e em outros tantos momentos de militância e trabalhos com a juventude capixaba.

Além da implantação do SUAS, naquele momento havia uma urgência nacional na elaboração de políticas de juventude, pois se constatava um expressivo aumento da violência que colocava os jovens pobres e negros da periferia como a maior vítima. E em resposta às demandas dos movimentos sociais em 2005 foram criadas a Secretaria Nacional de Juventude ${ }^{3}$ (SNJ), o Conselho Nacional da Juventude ${ }^{4}$ (CONJUVE) e o Programa Nacional de Inclusão de Jovens ${ }^{5}$ (PROJOVEM), como parte da Política Nacional de Juventude.

Além da adaptação ao SUAS, os Estados passaram a se organizar de acordo com a Secretaria Nacional de Juventude (SNJ). E aqui no Espírito Santo a SETADES, seguindo o formato nacional, incluiu em sua composição uma gerência que contemplava a criança, o adolescente e o jovem. Nessa gerência ocupei a função de Coordenadora Estadual de Juventude, na gestão estadual do ProJovem Adolescente e do Projeto Espaço 
Jovem. No período de 2004 a 2008 em que atuei como coordenadora estadual de juventude, ocupava a função que consistia em trabalhar junto aos municípios do estado do Espírito Santo (ES) assessorando na formulação de políticas públicas de juventude. Algumas destas políticas tinham seu formato definido pelo governo federal, outras eram formuladas em âmbito estadual e/ou municipal.

Naquela ocasião o governo estadual objetivava a construção de políticas de juventude no estado do ES. Era uma época em que se discutia a importância de "se ouvir a juventude", que fosse viabilizada a construção de políticas que inserissem "a fala do jovem", “o desejo do jovem", acreditava-se que diferente das formulações de políticas para crianças, "o jovem pode escolher o que quer". Pensava-se ser este o modelo mais adequado de construção de políticas para juventude, promovendo a suposta participação do jovem e denominando estes momentos como "espaços de escuta".

Contávamos com poucas experiências neste âmbito, ou seja, de elaboração de políticas de juventude, e o Estado tinha que formular suas proposições. Nosso trabalho se voltava aos municípios capixabas que seriam capacitados/formados/orientados para 'receber' tais políticas. O contato com os municípios se dava de muitas formas: por meio de reuniões, encontros, seminários, formações e visitas. Quando saíamos para as visitas construíamos em equipe uma metodologia de orientação para as equipes municipais e, em algumas vezes, para a "escuta do jovem". A proposição era de realizar um encontro no formato de uma roda de conversa, que permitisse o registro e a sistematização do que fosse dito por eles. A mobilização dos jovens era feita pelas equipes municipais e os jovens inseridos nestes encontros, em sua maioria, já participava de projetos do governo federal.

Os programas federais chegavam com seus traçados metodológicos definidos, bem produzidos, faltando apenas que o jovem fosse "encaixado" ali. Nas orientações às equipes municipais as profissionais expressavam alguns de seus anseios: "Não é fácil trabalhar com jovens, eles nunca querem nada, será que esse programa tem bolsa? Se não tiver, ficará difícil atrair o jovem." Um dos programas do governo federal direcionado a adolescentes e jovens fazia a concessão de uma bolsa para participação destes grupos em suas ações. Porém, com a modificação realizada, essa bolsa deixou de existir, criando-se um imenso incômodo sobre como trabalhar com a juventude sem usar o dinheiro para supostamente atraí-losPara muitos profissionais era difícil trabalhar com os jovens, 
considerados sempre difíceis, e o aporte financeiro era visto como uma ferramenta importante no controle da participação de jovens pobres.

Muitos planejamentos das ações foram centralizadas na região norte do estado onde estavam localizados os municípios com os menores Índices de Desenvolvimento Humano (IDH) ${ }^{6}$. Foram 29 municípios identificados pelo UNICEF no período de 2004 a 2009, sendo pactuado que o município que conseguisse alcançar a melhoria em seus indicadores de políticas públicas para crianças e adolescentes efetuando as ações propostas pelo UNICEF, receberia o Selo UNICEF. ${ }^{7}$ Para isso o UNICEF esteve no estado do ES por muitas vezes, formando as equipes estaduais para implantação deste Selo, iniciando uma grande disputa entre os municípios para a sua conquista. Circulamos pelos 29 municípios nas chamadas escutas aos jovens, essas conversas eram acompanhadas pelos técnicos municipais. Apostávamos na criação de espaços destinados a desenvolver ações com a juventude desde que fossem administrados pelos próprios jovens. Entendíamos que os debates nos municípios poderiam se tornar disparadores de elaboração de políticas para a juventude. Porém, tudo era construído de forma ligeira, as respostas deveriam ser rápidas, afinal de contas o dinheiro precisava ser utilizado.

E nesse fluxo, com grande acúmulo de trabalho e com uma equipe composta por pouquíssimos profissionais, ia seguindo uma rápida construção de políticas governamentais. Algumas ideias já haviam sido construídas no plano de ações da secretaria, mas o tempo era sempre curto para pensarmos o funcionamento e os efeitos das ações realizadas ou se de fato era aquele o caminho mais interessante a seguir. Hoje, analisando o processo experimentado, podemos perceber que tudo se organizava para que, de fato, uma escuta cuidadosa e a construção de políticas públicas com os jovens não se efetuassem de forma a acolher suas demandas e proposições.

\section{Gestão de vidas, políticas públicas e controle social: $O$ dispositivo Conferência de Juventude no Espírito Santo}

Estamos aqui nomeando as conferências como dispositivo partindo da compreensão formulada por Deleuze (1990) acerca das contribuições de Foucault acerca deste conceito. Este autor apontou que a noção de dispositivo em Foucault se constituía como um conjunto de linhas emaranhadas. Dentre elas citamos aqui as linhas de visibilidade e de enunciação, que conferem ao dispositivo um caráter de máquina de “fazer ver e fazer falar" (DELEUZE, 1990). Foucault apontava que um dispositivo incluía um conjunto misto e heterogêneo de elementos: “discursos, instituições, organizações 
arquitetônicas, decisões regulamentares, leis, medidas administrativas, enunciados científicos, proposições filosóficas, morais, filantrópicas. Em suma, o dito e o não dito são os elementos do dispositivo [...]" (FOUCAULT, 1996: 244-245). O que nos interessa neste debate é como o dispositivo-conferência faz ver e faz falar certos modos de participar e de pensar a juventude, regulamenta modos de fazer políticas públicas, além de delinear quais problemas e demandas podem ser pautados nos debates.

No período pós-ditatorial, segundo Souza (2012), mesmo com a incerteza da garantia de direitos sociais de cidadania, o que se observou foi uma nova organização das estruturas institucionais para a inclusão dos cidadãos na gestão pública (DAGNINO, 1998), interferindo na formulação e no controle da implementação de políticas públicas ${ }^{8}$. Justifica-se assim a criação de estruturas diferenciadas para a participação política como parte de um esforço para tornar as instituições estatais mais democráticas e inclusivas.

De acordo com Souza (2012), foi ainda em 1937 que a legislação brasileira previu as conferências para área de saúde e educação a partir da Lei N³78 de 13/01/1937. Foi realizada em 1941 a primeira Conferência Nacional de Saúde, que reuniu representantes das esferas federal e estadual que discutiam e decidiam sobre questões administrativas no campo da saúde pública. Nessa época a discussão era restrita aos agentes estatais.

Mas, foi com o fim da ditadura militar que esse movimento de participação na gestão das políticas públicas foi impulsionado incluindo os cidadãos, organizações e movimentos sociais, a chamada sociedade civil. O texto constitucional trouxe novos elementos surgidos na sociedade, nas instituições emergentes, abrindo espaço para a democracia participativa, que ampliava direitos políticos e incentivava uma gestão pública participativa com toda sociedade.

No processo de redemocratização do país diversas experiências foram surgindo, principalmente através da criação de conselhos gestores e orçamento participativo. Com a amplitude desses espaços, outros modos e formatos de organização e participação da sociedade civil foram ocorrendo, abrindo canais para gestão pública e participativa, com a formação de conselhos e conferências. $O$ formato de gestão participativa tem início com o SUS, e esse formato abriu caminho para criação de processos participativos em âmbito nacional, em várias áreas e formatos, um dos formatos foram as conferências ${ }^{9}$. As Conferências foram definidas como processos participativos que deveriam reunir com periodicidade os representantes do estado e da sociedade civil, visando a formulação de propostas para uma determinada política pública. 
Com a contribuição de Souza (2012), tendo como base de análise às conferências realizadas no período do governo Lula, podemos perceber que a dinâmica de organização de uma conferência mudava de acordo com o contexto, mas há pontos em comum. De forma geral, as conferências são convocadas com caráter consultivo ou deliberativo, pelo poder executivo de cada esfera de governo. Em formato de decreto o poder executivo define o tema da conferência e o órgão responsável pela organização. Quando previsto em lei, o próprio conselho do tema referente à conferência pode fazer o chamamento. Os órgãos responsáveis definem a comissão organizadora, o período e o formato de sua realização.

A comissão organizadora é uma instância temporária que inclui diversos segmentos representados, cabe a esta comissão discutir as estratégias e o cronograma de ação de uma conferência, é uma ação dedicada exclusivamente para a tarefa de realização de uma conferência. A comissão também elabora o regulamento e estabelece as etapas do processo. Na maior parte dos casos a comissão também produz o regimento interno da conferência que será apreciado em plenária do evento. (SOUZA, 2012)

As etapas de realização de uma conferência podem ser municipais ou regionais, e ter bases territoriais variadas dependendo da temática a ser debatida. Quando os chamamentos são nacionais, há etapas estaduais de discussões prévias e escolhas dos representantes (chamados de delegados), na maior parte das vezes representantes escolhidos nas etapas municipais. As discussões em uma conferência são orientadas por um texto base que provoca as discussões sobre a temática a ser abordada, e podem trazer também as propostas do governo para aquele setor. (SOUZA, 2012)

O mais comum nas conferências são as chamadas plenárias e grupos temáticos, que discutem o que está colocado no texto base. O modo de organização das falas dos participantes em uma conferência se dá por ordem de fala que é feita por ordem de inscrições; as falas podem ser favoráveis, contrárias, podem suprimir, modificar ou adicionar algo no texto base proposto.

Ao final da conferência sistematiza-se as propostas que serão levadas à plenária para serem votadas pelos delegados, que são os representantes que tem direito a voz e voto. Em alguns casos a comissão organizadora pode indicar convidados, que têm direito a voz e também participantes observadores. As decisões da plenária final são chamadas de deliberações ou resoluções, e cabe ao órgão responsável pela conferência dar encaminhamento às mesmas para que possam compor na formulação ou aprimoramento de uma determinada política pública. 
Nosso percurso como trabalhadora social nas políticas públicas nos mostrou que quando se fala em construção de políticas públicas de juventude, o modo tradicional de fazer política estatal entende que caberia aos atores públicos (gestores públicos e técnicos da área) a tarefa da convocação da juventude para os ditos espaços de participação e de fala. Inicia-se, assim, no planejamento de caminhos para construção das políticas públicas de juventude, a convocação do jovem que supostamente contribuiria nos ditos espaços de participação. Estaria à juventude disposta a dialogar sobre a construção dessas políticas efetuadas ainda de forma verticalizada? Como os jovens seriam escutados em espaços já pré-definidos para suas falas?

Essa movimentação teve seu começo em âmbito nacional por meio de órgãos públicos (governo federal, estaduais e municipais) que aderiram a um chamado do governo federal. No Espírito Santo/ES esse momento teve início nos anos 2000, período também que por meio de programas propostos pelo governo federal algumas ações foram executadas pelos municípios. Em Vitória, capital do ES, além de projetos do governo federal algumas políticas de juventude de iniciativa municipal se consolidavam, como o Centro de Referência da Juventude (CRJ) e o Núcleo Afro Odomodê ${ }^{10}$. Esses projetos eram desenvolvidos pela gerência de juventude, vinculada à secretaria municipal de assistência social de Vitória/ES. Outros municípios do estado começaram também a instituir gerências e coordenações de juventude. Como ainda estavam iniciando uma atuação com este segmento, a maior parte dos municípios implementava os projetos do governo federal voltados para adolescentes, sendo que estes projetos chegavam com suas metodologias já definidas.

\section{As Conferências de Juventude no Espírito Santo}

No Espírito Santo o processo de elaboração da I Conferência Estadual de Políticas Públicas de Juventude teve início no ano de 2007. Nesse período o Estado contava com uma estrutura ainda inicial no que se refere à existência de secretarias, conselhos, coordenações e gerências voltadas às políticas públicas de juventude. Em todo o Estado poucos eram os municípios que possuíam secretarias ou setores dedicados às políticas públicas de juventude. Dos municípios que compunham a Região Metropolitana da Grande Vitória ${ }^{11}$, apenas Vitória, Cariacica e Vila Velha dispunham de conselhos municipais de juventude e/ou de coordenações e gerências voltadas para o público jovem. Cariacica possuía uma coordenação de juventude e o município de Vila Velha também 
criou uma gerência de juventude. Os municípios de Fundão, Guarapari, Serra e Viana, não contavam com estruturas de conselhos, gerências ou coordenações de juventude.

Em âmbito estadual existia em 2007 a assessoria de atenção à criança, ao adolescente e à juventude (AECAJ), parte da Secretaria de Estado de Trabalho, Assistência e Desenvolvimento Social (SETADES). Essa assessoria respondia por políticas públicas em formatos de programas e projetos voltados para a criança, o adolescente e o jovem. Desta forma, na esfera estadual, a gestão das políticas públicas de juventude se concentrava nessa assessoria. Sendo também responsável por todo o processo de coordenação da conferência estadual, que inclusive possuía rubricas orçamentárias especificas para as ações a serem efetuadas com a juventude.

Coube assim à AECAJ a tarefa de efetuar as articulações para garantir e viabilizar a realização da I Conferência Estadual de Políticas Públicas de Juventude. Naquela ocasião a SETADES também possuía o Núcleo de Avaliação de Políticas Sociais Integradas e de Capacitação (NAPSI), um setor que tinha como uma de suas atribuições a organização de toda estrutura e logística de conferências realizadas no âmbito da secretaria. E para a conferência de juventude esse setor esteve junto na viabilização de todo evento.

Em 2007 o governo federal convocou a realização da I Conferência Nacional de Políticas Públicas de Juventude. Como apontado acima, todo chamamento de uma conferência segue um modo de organização próprio. O governo federal já possuía instituídos a Secretaria Nacional de Juventude e o Conselho Nacional de Juventude, e foi pelo conselho que ocorreu a convocação para a participação dos níveis municipais e estadual.

Na esfera federal o processo de realização da I Conferência Nacional de Juventude buscou contemplar tanto os modos de participação pelos municípios e pelo estado, quanto as formas sem limite territorial que pudessem considerar a diversidade de modos de vida da juventude. Sendo assim foram desenvolvidas etapas territoriais como as conferências municipais, estaduais, do Distrito Federal e nacional, além das conferências livres e de uma consulta aos povos de comunidade tradicionais.

Segundo Castro e Abramovay (2009), a organização de todo processo metodológico da conferência de juventude teve como objetivos fomentar o debate sobre o tema; difundir informações sobre os três eixos da Conferência (Democracia, Participação e Desenvolvimento Nacional, Parâmetros e Diretrizes da Política Nacional de Juventude, Desafios e Prioridades para as Políticas Públicas de Juventude); e 
possibilitar a Formulação de Propostas de Políticas Públicas. Para viabilizar esse processo foram criados materiais de apoio como os cadernos temáticos, o documento base da conferência, o manual da comissão organizadora, os modelos de relatórios, além de orientações para utilização de um modo de condução que ajudasse a qualificar as propostas discutidas. Seguindo essas diretrizes cabiam às comissões organizadoras (nacional, estaduais e municipais) a realização de todo evento da conferência, bem como a garantia de cumprimento dos cronogramas e orientações contidas nos documentos norteadores.

O ES não possuía instaurado o conselho estadual de juventude, por isso seguiu a proposição do governo federal e fez o chamamento pela Comissão Organizadora Estadual, que iniciou sua atuação em 2007. A primeira atividade foi a realização de um evento/encontro para convidar os municípios do estado para adesão a I Conferência de Juventude. O evento foi realizado no espaço do Serviço Social do Transporte e o Serviço Nacional de Aprendizagem do Transporte (SEST/SENAT) do município de Cariacica. Neste evento foram apresentadas as propostas da I conferência nacional, com suas orientações e documentos norteadores. O objetivo do encontro foi fomentar nos municípios a importância da adesão ao processo de realização das conferências.

Iniciava-se no país o debate em torno das políticas públicas de juventude, e o acontecimento da conferência viria contribuir no conhecimento e fortalecimento para a constituição de políticas de juventude. Sendo assim, o encontro também teve como objetivo apresentar aos municípios o espaço criado em âmbito estadual para uma dedicação às políticas públicas de juventude. E também contar com os municípios na articulação para desenvolver ações com a juventude promovidas pelo governo estadual. O ES possuí 78 municípios e mais da metade dos municípios aderiu à conferência.

O processo de chamamento da conferência, o convite para adesão dos municípios, a realização de um número expressivo de conferências em todo estado, alcançando grupos diversos (pescadores, pomeranos, quilombolas, índios, comunidades de terreiros) e, por fim, a realização da conferência estadual, foram percursos que de fato fomentaram a criação e fortalecimento de políticas públicas nos municípios do ES, tais como: conselhos, fóruns, secretarias, gerências e coordenações. A movimentação daquele período, desde o âmbito federal, colaborou para que tivessem início debates e ações com esse grupo populacional, indicando que haveria uma atenção inicial às suas demandas e urgências. 
Enquanto trabalhadores em políticas públicas de juventude nos agitava o momento de estarmos com a juventude para “ouvirmos o jovem”, "tínhamos que mobilizá-los” para aquela participação. Essas eram muitas das frases repetidas por nós. Estávamos na organização de uma conferência, tratava-se de um lugar que entendíamos como legitimado para construção de políticas públicas. Mas como podemos pensar esse dispositivo de participação e de escuta? Seria esse o único ou principal dispositivo legitimado de fala? O que tornava este dispositivo-conferência legítimo? O que este dispositivo-conferência fazia ver e fazia falar? O que nomeamos como escuta e como espaço de participação?

A maioria dos jovens que esteve nos espaços da I Conferência era constituída por jovens negros pobres, moradores das periferias de todo Espírito Santo. Foram mobilizados ou convidados por profissionais dos conselhos, comissões, gerências ou coordenações de governos municipais. As gerências e coordenações municipais, por meio dos seus gestores e técnicos, é que fariam o convite para esses espaços, eram os profissionais que iriam orientá-los sobre aquele momento. A referência era sempre a do saber profissional para esse convite. Com a organização de como iria acontecer e do que pretendíamos, foram criados os tais "espaços de fala dos jovens".

Podemos aqui fazer uma analogia com o que Foucault (1998) diz a respeito da relação dos intelectuais com as massas. A descoberta de que as massas não necessitam dos intelectuais para saber, elas sabem muito melhor do que eles. Contudo, há um sistema de poder que barra e invalida esse discurso e esse saber. Não deve ser esse o papel do intelectual, de dar voz ao que está mudo, mas ele deve ser sim a força de luta contra as formas de poder onde ele está, ao mesmo tempo, como objeto e instrumento. Pautávamos nossa atuação em um compromisso profissional de fazer emergir falas sobre aquele momento. Hoje percebo que seria necessário delinear algumas indagações: Estavam os jovens mudos antes de nossa proposição? Até onde o modo como utilizávamos esse saber dificultou ou até mesmo impediu outras tantas formas de expressão?

\section{Do processo de organização e realização das conferências municipais}

Havia em nós, profissionais que atuavam nos setores e órgãos envolvidos com políticas de juventude, uma ansiedade para que tudo pudesse transcorrer em um ambiente que os jovens estivessem supostamente livres para dizer de suas dificuldades, de suas vidas, das demandas de seus municípios. Trabalhávamos na garantia desses espaços como se fossemos os fios condutores daquele processo. Contudo, a cada ação que efetuávamos, 
de alguma forma engendrávamos uma participação que em muitas situações estiveram atravessadas por práticas de tutela e de controle de acordo com o que estava previamente definido como lugar de fala, tempo de fala, tema a ser debatido, etc.

E nessa organização foi criada a Comissão Organizadora Estadual, composta por representantes da sociedade civil e do poder público. Para a criação desse espaço muitos caminhos foram pensados, mas o principal era de que ali deveriam estar representados o que chamávamos de "as juventudes", que eram as várias expressões de juventude, ou seja, grupos ou manifestações de jovens de segmentos diversos, a saber: a juventude do hip hop, do funk, do skate, do graffiti, dos movimentos estudantis, grupos ou fóruns de juventude negra, a juventude das pastorais, as evangélicas, etc.

A criação da comissão partia da divisão entre poder público e sociedade civil. $\mathrm{O}$ poder público estava bem definido com representantes de municípios que possuíam conselhos, gerências e/ou coordenações de juventude. Mas e a sociedade civil? As "juventudes" seriam identificadas e, para isso, contamos com o apoio da gerência de juventude do município de Vitória, que já dispunha da existência dos centros de referência e poderia identificar alguns grupos na cidade.

A gerência deste município possuía uma frente de trabalho chamada Rede Jovem, que buscava na cidade manifestações da juventude e promoviam eventos com recursos da prefeitura, tendo esses grupos de jovens como protagonistas. $\mathrm{Na}$ Comissão Organizadora Estadual, os representantes do poder público já se destacavam como militantes no campo das políticas públicas de juventude nos municípios da Grande Vitória. Todos eram considerados agentes que possuíam "o saber sobre a juventude" e foram pessoas atuantes em seus municípios para a adesão às políticas para este grupo.

Alguns grupos foram indicados pela Comissão Nacional da Conferência, grupos de juventude que na elaboração da Conferência foram previstos para serem alcançados, tais como: juventudes de terreiros, quilombolas, índios, pescadores e os povos de floresta. E assim incluímos movimentos estudantis, fórum de juventude negra, LGBT’S, comunidade de terreiros, hip hop, pastoral da juventude, juventude evangélica.

Com a composição da comissão definida, o lançamento da conferência e a adesão dos municípios, teve início a realização das etapas municipais. Os membros da Comissão Organizadora Estadual se dividiram no apoio aos municípios. Após as mobilizações dos jovens nos municípios chegávamos como representantes da comissão estadual. Para cada município iam no máximo dois representantes da comissão, sendo um responsável pela 
realização de uma palestra e o outro atuava como apoio às comissões municipais na condução da conferência. A palestra abordava a contextualização do que é uma conferência, como funcionava, para que foi criada, e a importância das políticas públicas de juventude. Mostrávamos aos jovens os indicadores de desemprego, escolarização, saúde, violência. Ou seja, ali se produzia uma demanda por certas políticas públicas, se delineava os tais "supostos reais" problemas da juventude. Uma máquina de fazer falar as questões da juventude ia se engendrando nas ações que antecediam a conferência.

Anteriormente a essa chegada, os municípios tinham a função de mobilizar os jovens que iriam participar, assim como preparar toda infraestrutura do evento. Por vezes, a pedido dos gestores municipais, contribuíamos orientando como poderia se dar a mobilização dos jovens, mas tentávamos indicar que esse fosse um movimento do próprio município. Porém, hoje vejo que toda essa forma tão bem traçada de métodos, fluxos, ordem e condução do processo de participação estava voltada para um determinado público. Ou seja, a metodologia de organização da conferência circunscrevia quais grupos de jovens iriam participar, quais teriam espaço de fala.

Logo na sua chegada, os jovens se inscreviam e já escolhiam o grupo de trabalho com o tema de seu interesse. Havia uma oferta de 12 temas já definidos: "Educação", “Trabalho", "Cultura", "Sexualidade", "Participação", "Meio Ambiente”, "Diversidade", “Tempo Livre", "Mídia", "Drogas”, "Cidades" e "Família”. Cada tema tinha um número limitado de vagas, depois de preenchidas as vagas de um tema os jovens deveriam escolher outros temas com vagas disponíveis. Não era possível incluir outros temas além dos já definidos. Cada grupo de trabalho possuía um facilitador que, em sua prática profissional, tinha conhecimento ou aproximação com o tema. A função do facilitador era a mediação dos debates e orientação para definição e sistematização das propostas dos grupos.

A metodologia de funcionamento já interferia no modo como os jovens participariam deste encontro. Em cada grupo temático deveriam pensar propostas para os temas e existia uma planilha que seria preenchida pelos facilitadores. Cabia ao facilitador filtrar, orientar e sistematizar o que seria inserido como proposta. Ao final do debate estavam definidas as propostas que seriam levadas à plenária por cada grupo e escolhido o relator. Cada grupo deveria encaminhar 06 propostas. Após este momento os grupos retornavam para a plenária apresentando as propostas elaboradas pelo relator escolhido. Na plenária, as propostas eram votadas e ali também se definia quem seriam os delegados para conferência estadual. 
A movimentação para a escolha e o momento da eleição dos delegados para a conferência estadual já se dava durante a realização das conferências municipais. Articulações partidárias e grupos de interesse diversos se moviam, montando estratégias e tentando conduzir também as propostas que seriam votadas pelos jovens, bem como definir quem seria escolhido como delegado. Ou seja, todo o processo de organização e realização da conferência estadual se constituiu em um terreno de muitos tensionamentos e interesses diversos.

Foram muitas as reuniões para efetuar a elaboração de uma longa programação de 03 dias de conferência estadual. O governo do estado, por meio da secretaria de assistência social, possuía a rubrica financeira para viabilizar toda a estrutura do evento. A conferência foi realizada no Serviço Social do Comércio (SESC) de Santa Cruz/ES, com hospedagem e alimentação para 500 participantes, durante os 03 dias de atividades.

Com uma extensa programação, a comissão construiu junto a esta gerência especifica, o NAPSI, como seria cada dia da conferência e sua finalização com a definição das propostas do estado do ES, e a eleição de delegados para a etapa nacional. Na comissão foram indicados os facilitadores dos 12 temas pré-determinados, tendo 01 facilitador para cada tema, levando-se em consideração a experiência e o conhecimento curricular significativo sobre o referido tema. Foi formado um grupo de profissionais para condução dos grupos de trabalho por temática.

A conferência teve início com uma mesa de abertura formal, contando com a participação do governo federal, com os representantes da comissão organizadora nacional, as secretarias estaduais, representantes da assembleia legislativa, bem como os gestores municipais. Os jovens de comunidades de terreiros, os jovens quilombolas, os jovens índios de Aracruz, os jovens pescadores, os jovens pomeranos, trouxeram muito do seu viver, e naquele espaço se colocaram também. Temos que dizer da importância que foi a garantia desses grupos na formulação da conferência, por mais que fosse um movimento ainda pequeno, foi imensa aquela troca.

A participação nos grupos de trabalho se deu forma intensa e bem ativa. Os jovens que vieram representando os seus municípios apresentaram muito de suas realidades locais, expressando a diversidade de modos de vida em seus territórios. Os debates em plenária dos temas trazidos pelos grupos foram momentos de grande intensidade. A conferência se efetuou entre exercícios de participação e estratégias de cooptação e silenciamento dos jovens e transcorreu com o "sucesso esperado". A eleição de delegados 
para a conferência nacional se deu de forma intensa, com muita interferência de grupos políticos, mas também com muitos posicionamentos de jovens que ali se organizaram e se conheceram. O Fórum Estadual da Juventude Negra (FEJUNES) estava iniciando suas ações, e esse espaço também foi importante para essa consolidação. O FEJUNES teve uma atuação relevante e destacada na implementação de políticas voltadas à juventude e na formulação de denúncias acerca do extermínio da juventude negra capixaba. O estado do ES teve 39 delegados eleitos na conferência estadual para representação na conferência nacional, que ocorreu no mês de abril de 2018. A Conferência Nacional reuniu aproximadamente 2500 jovens.

\section{Inquietações provocadas nas Conferências}

Os espaços modulados e planejados para o funcionamento das conferências, compreendidas como espaços privilegiados de participação social, podem nos levar a operar com uma substituição de antigas técnicas para novas moldagens biopolíticas de controle dos corpos, que não se dará apenas num ambiente de realização de conferências, mas também num tipo de funcionamento e construção de políticas públicas. Em muitas situações estávamos atravessadas por certo ideal de participação que deve se dar de forma organizada, ordeira. Contudo, vemos que a juventude está constantemente criando modos e jeitos de participação na sociedade para além de espaços instituídos, para além do controle dos seus corpos e modos instituídos de vida. Mas não era apenas isso o que se deu nas realizações das conferências. Atribuía-se a participação na conferência ao mero fato de estar presente naquele local, naquele horário, seguindo as orientações protocolares de uma conferência. Então, até onde podemos pensar em participação quando definimos as formas de participar, que acabam por nos cegar diante do que realmente atravessa e move os jovens?

As variadas formas de expressão dos jovens e o modo como se colocam ou não nesses espaços diz de um modo de participação que está para além das formalidades impostas nos cadernos de orientações de uma conferência. $\mathrm{O}$ olhar mais atento e a escuta aguçada vão apontar que os jovens participam a todo tempo, de modos diversos e em todos os lugares.

Muitas ocorrências impediram que nos atentássemos para a dimensão micropolítica da conferência se efetuando. Constantemente eu era retirada para assumir funções de mediação de grupos políticos que insistiam na "derrubada da conferência". Havia uma rivalidade colocada frente a conferência estar sendo proposta pelo governo 
Lula, também nesses espaços os partidos tradicionais de direita criavam enfrentamentos. Utilizava-se do regimento que passava pela aprovação da plenária para, através dele, criar entraves para o andamento da conferência.

Analisando hoje o que se passou, percebo que as conferências se efetuaram também como um modo de regulamentação dos modos de participação da juventude na proposição de políticas públicas. Partia-se de noções já naturalizadas: cidadania, cidadão de direitos, modos de participar, política estatal como sinônimo de políticas públicas, dentre outras questões.

As conferências funcionaram como um dispositivo de fazer ver e fazer falar o modo como a máquina estatal regulamenta os processos de participação: o que vai ser discutido e o que vai ser definido e proposto já está esboçado. Isso efetua um esvaziamento dos processos de participação, uma despotencialização da interferência dos jovens nos rumos das políticas que lhes são dirigidas.

O debate efetuado por Heckert (2007) nos enriquece com o modo com que forjamos nossas escutas. Ou seja, afirmamos que estamos operando na direção da participação, de uma escuta que os jovens traziam, mas na verdade estávamos capturados por muitas instituições. Tudo tinha um modo de funcionar muitas vezes nos levando a não perceber os desassossegos, os desconfortos, as capturas. O que incomodava e inquietava eram atravessamentos de uma organização protocolar. Passados alguns anos, num esforço de ativar a memória do que se passou nestas conferências, percebo que estávamos pouco atentos a escutar o que desviava dos procedimentos, temas, cronograma. Os temas, procedimentos e cronogramas não engessavam apenas os jovens, também regulamentava e delineava as nossas ações como técnicos a tal ponto que o que desviava pouco foi ouvido por nós. Não percebemos que estes procedimentos engessavam, contornavam e produziam o que era dito e o que seria silenciado.

Não que não tenha havido escapes, resistências e derivas durante o processo das conferências. Certamente estas derivas ocorreram. Mas todo o seu processo de constituição partiu de certas noções já naturalizadas: cidadania, cidadão de direitos, política estatal como sinônimo de políticas públicas, e a própria definição do que é a juventude. Porém, não podemos deixar de ressaltar que as conferências também se construíram como fomento à variação de ações e programas governamentais, voltados à juventude. O dispositivo conferência impulsionou a criação e/ou fortalecimento de conselhos de juventude, gerências, coordenações e fóruns. 
Porém, assistimos também à intensificação de procedimentos de regulamentação da vida dos jovens negros e pobres. Na última década do século XX e a primeira década do século XXI vemos a ampliação da lógica punitiva sendo direcionada aos jovens pobres. Se de um lado houve um incremento à construção de políticas sociais voltadas à juventude, vimos também as políticas de segurança se tornando cada vez mais o procedimento estatal por excelência direcionada aos jovens negros e pobres.

Hoje, mais de dez anos depois da realização da conferência nacional de juventude, nos transportamos para uma conjuntura política dura, conservadora, em que a juventude vem morrendo ainda mais, comparecendo nos tais indicadores que não param de crescer. Vidas de jovens pobres e negros indo embora, num plano macabro de extermínio da juventude negra de periferia que vai tomando mais força, com novas roupagens, com jovens sendo mortos. Nesse novo tempo, as políticas de juventude foram ainda mais fragilizadas. Espaços de conselhos que por um tempo resistiam para se manterem acabaram perdendo força de luta, muitos deles se enfraqueceram. Poucas ou quase nenhuma ação no campo das políticas de juventude se mantém. O município de Vitória que possuía serviços fortalecidos na cidade também passa por uma paralisação de alguns desses espaços.

Porém, muitos coletivos, grupos e ações vêm sendo protagonizadas por jovens na Grande Vitória. Ações que atacam o racismo e o consequente exterminio da juventude negra, que enfrentam a violência contra as mulheres, que denunciam a perversa criminalização da juventude negra. Ao mesmo tempo em que vivemos o enfraquecimento e a destruição das políticas estatais, experimentamos também novos e inusitados modos de luta que os jovens vão criando, e assim tecem no chão das ruas políticas públicas de proteção e acolhida de seus modos de vida que sempre irão variar de forma potente. Apesar dos fascismos, juventudes inventam outros presentes.

\section{Referências}

BRASIL. CONSELHOS DE JUVENTUDE: fortalecendo diálogos, promovendo direitos. Conselho Nacional de Juventude. Brasília, maio/2010. Disponível em: https://bibliotecadigital.mdh.gov.br/jspui/handle/192/187 (Acesso em 20/05/2018).

BUSSINGUER, Elda C. de A.; NEVES, Edilene S. da S. Juventude e Políticas Públicas: bônus ou oportunidades, perdidas? Revista de Direitos e Garantias Fundamentais. Vitória, v. 17, n. 2, p. 241-292, jul./dez. 2016.

CASTRO, Mary. G; ABRAMOVAY, Miriam. Quebrando mitos: juventude participação $e$ políticas. Perfil, percepções e recomendações dos participantes da $1^{a}$ Conferência Nacional de Políticas Públicas de Juventude. Brasília: Ed. RITLA, 
2009.

COIMBRA, Cecília. M. Bouças. (1995). Os caminhos de Lapassade e da Análise Institucional. Revista do Departamento de Psicologia da Universidade Federal Fluminense, 7(1), 52-80.

COIMBRA, Cecília. M. B. e NASCIMENTO, Maria. L. do (2004). Sobreimplicação: práticas de esvaziamento político?. Disponível em http://www.slab.uff.br/images/Aqruivos/textos_sti/Cec\%C3\%ADlia\%20Coimbr a/ texto22.pdf. Acesso em 30/06/2015.

DAGNINO, Evelina. Sociedade civil, participação e cidadania: de que estamos falando? En MATO. D (coord.), Políticas de ciudadania y sociedad civil em tiempos de globalización. Caracas: FACES, Universidad Central de Venezuela. 2004. P 95110.

DELEUZE, Gilles. O que é um dispositivo? In: DELEUZE, G. Michel Foucault, filósofo. Barcelona: Gedisa, 1990, p. 155-161. Disponível em: http://escolanomade.org/2016/02/24/deleuze-o-que-e-um- dispositivo/. Acesso em 20 janeiro de 2019.

FOUCAULT. Michel. Sobre a História da Sexualidade. In: FOUCAULT, M. Microfísica do poder. Rio de Janeiro: Graal, 1996.

FOUCAULT. Michel. Em defesa da Sociedade. São Paulo; Martins Fontes, 1999.

FOUCAULT, Michel. Nascimento da biopolítica. São Paulo: Martins Fontes, 2008.

FOUCAULT, Michel. História da sexualidade I: a vontade de saber. 22. ed. Rio de Janeiro: Graal, 2012.

HECKERT, Ana. L. C.; BARROS, Maria. E.B.; CARVALHO, Silvia.V. Cidades e Políticas Públicas. Fractal: Revista de Psicologia, v.28, n.2, p. 266-274, maioagosto, 2016.

HECKERT, Ana. L. C. Escuta como Cuidado: o que se passa nos processos de formação e de escuta? In: PINHEIRO. R; MATTOS, R.A. (Org.) Razões públicas para integralidade em saúde: o cuidado como valor. 1 ed. Rio de Janeiro: ABRASCO/CEPESC, 2007, v. 1, p. 199-212.

HECKERT, Ana.L. C. Narrativas de Resistências: Educação e Políticas. Tese de Doutorado (Doutorado em Educação) - Programa de Pós-Graduação em Educação, Universidade Federal Fluminense, Niterói, 2004.

INSTITUTO DE PESQUISA ECONÔMICA. IPEA. Juventude levada em conta: demografia. 2013. Disponível em: http://www.ipea.gov.br/portal/index.php?option=com_content\&view=article\&id=21447 . Acesso em 22/11/2018.

LARROSA. Jorge. Experiência e alteridade em educação. Revista Reflexão e Ação, Santa Cruz do Sul, v. 19, n2, p.04-27, jul./dez. 2011. Disponível em: https://online.unisc.br/seer/index.php/reflex/article/view/2444. Acesso em 30 de setembro de 2020.

LOURAU, Rene. (2004a). Implicação e Sobreimplicação. Em S. Altoé (Org.), Renê Lourau: Analista Institucional em Tempo Integral. (pp.186-198). São Paulo: Hucitec. 
LOURAU, Rene. (2004b). O Estado na Análise Institucional. Em S. Altoé (Org.), Renê Lourau: Analista Institucional em Tempo Integral (pp.140-153). São Paulo: Hucitec.

MIGUEL, Ricardo. M. Projovem Adolescente em Venda Nova do Imigrante - ES e a vida dos jovens: conexões, capturas, escapes e aproximações. Dissertação de mestrado (Mestrado em Psicologia Institucional) - Programa de Pós-Graduação em Psicologia Institucional, Universidade Federal do Espírito Santo, Vitória, 2014.

PASSOS, E.; BARROS, R. A humanização como dimensão pública das políticas de saúde. Rio de Janeiro: Ciência \& Saúde Coletiva, vol.10, n 3, Jul/Set, 2005.

SADER, Emir. S. O público, o estatal e o privado. In: HEIMAN, L. S.; IBANHEZ, L. C.; BARBOZA, R. (Org.). O público e o privado na saúde. São Paulo: Hucitec, 2005. p. 43-56.

SCHEINVAR, Estela; CORDEIRO, Denise. Juventude em "risco social"? Dilemas e perspectivas por entre as pedras das políticas públicas dirigidas aos jovens. Espaço: informativo técnico científico do INES, n 27, jan-jun , p.55- 63, 2007.

SOUZA, Clovis. H. L. A que vieram as conferências nacionais? Uma análise dos objetivos dos processos realizados entre 2003 e 2010. IPEA. Secretaria de Assuntos Estratégicos da Presidência da República. Rio de Janeiro, 2012.

SOUZA. Clovis.H. L; AVRITZER, Leonardo. Conferências Nacionais: atores, dinâmicas participativas e efetividade. IPEA. Secretaria de Assuntos Estratégicos da Presidência da República. Rio de Janeiro, 2013.

SPOSITO, Marília. P.; CARRANO, Paulo. C.R. Juventude e Políticas Públicas no Brasil. Revista Brasileira de Educação, Rio de Janeiro, n² 24, Set /Out/Nov /Dez 2003.

Mônica Patrícia Gomes Machado Universidade Federal do Espírito Santo

Email: monicapgm@gmail.com

Ana Lúcia C. Heckert

Universidade Federal do Espírito Santo

Email: anaheckert@uol.com.br

\footnotetext{
1 Voltando ao século XX e à vigência dos Códigos de Menores, percebemos nesta época uma forte preocupação com a disciplinarização das crianças pobres, com a necessidade de colocar em ordem os "desviados" ou aqueles que poderiam vir a ser. Para estes, o espaço jurídico prevê a reeducação, a internação e a preparação para o trabalho. No conjunto dessas medidas, chamadas de proteção, o Estado vai construindo um modelo do que diz ser a assistência à pobreza. (Coimbra e Nascimento, 2005)

${ }^{2}$ A noção de autonomia aqui utilizada se pauta nas contribuições de Heckert (2004, quando afirma que a autonomia não é um estado, mas um exercício permanente. (HECKERT, 2004, p. 156)

${ }^{3}$ A Secretaria Nacional de Juventude era um órgão da Secretaria Geral da Presidência da República, que tinha o objetivo de gerir e articular as políticas direcionadas aos jovens dentro do governo e junto à sociedade (CONJUVE, 2010, p. 8). No governo Bolsonaro esta secretaria foi vinculada ao Ministério da Mulher, da Família e dos Direitos Humanos.
} 
${ }^{4}$ O Conjuve era um órgão ligado à Secretaria Geral da Presidência da República. Espaço privilegiado para a interlocução e cooperação entre diversos atores, o Conselho reunia 60 membros, sendo 20 do poder público e 40 da sociedade civil. (BRASIL, 2010, p. 8-9). No Governo Bolsonaro o CONJUVE passou a ser composto por 30 conselheiros, sendo 10 representantes do poder público e 20 representantes da sociedade civil. https://bibliotecadigital.mdh.gov.br/jspui/handle/192/187

${ }^{5}$ O programa que compõe a Política Nacional tem como objetivo proporcionar a formação integral aos jovens, por meio da associação entre formação básica, qualificação profissional e participação cidadã. Compreende quatro modalidades: ProJovem Adolescente, ProJovem Urbano, ProJovem Campo e ProJovem Trabalhador (BRASIL, 2010, p.8). https://bibliotecadigital.mdh.gov.br/jspui/handle/192/187

${ }^{6}$ O Índice de Desenvolvimento Humano (IDH) compara indicadores de países nos itens riqueza, alfabetização, educação, esperança de vida, natalidade e outros, com o intuito de avaliar o bem-estar de uma população, especialmente das crianças. Varia de zero a um e é divulgado pelo Programa das Nações Unidas para o Desenvolvimento (Pnud) em seu relatório anual. Na divulgação feita em novembro de 2007, com dados referentes a 2005, o Brasil pela primeira vez alcançou o nível 0,80, passando a integrar o grupo de países com IDH elevado. Países com IDH até 0,499 são considerados de desenvolvimento humano baixo, e os com índices entre 0,50 e 0,799 são considerados de desenvolvimento humano médio. (IPEA)

${ }^{7}$ Selo UNICEF é uma iniciativa do Fundo das Nações Unidas para a Infância - UNICEF voltada à redução das desigualdades e à garantia dos direitos das crianças e dos adolescentes previstos na Convenção sobre os Direitos da Criança e no Estatuto da Criança e do Adolescente (ECA). Ao participar do Selo UNICEF, os municípios assumem o compromisso de elaborar diagnóstico da situação de crianças e adolescentes e um Plano Municipal de Ação para enfrentar problemas que afetam essa população. Os municípios se comprometem a desenvolver ações nas áreas de saúde, educação, proteção e participação social e a monitorar os resultados alcançados por meio de indicadores e de debates em fóruns comunitários. Os municípios certificados pelo Selo UNICEF passam a fazer parte de um grupo de municípios reconhecidos internacionalmente pelo UNICEF por seus avanços em favor da infância e adolescência.

${ }^{8}$ Alguns autores têm efetuado um esforço no sentido de discernirem acerca dos diversos sentidos de políticas de estado, políticas governamentais e políticas públicas (PASSOS e BARROS, 2005; HECKERT, BARROS e CARVALHO, 2016; SADER, 2005). Nesses trabalhos chamam atenção para certa sinonímia que vem sendo estabelecida entre políticas públicas e políticas estatais. Indicam que políticas estatais não são necessariamente públicas, uma vez que o Estado não é um ente neutro, mas campo de disputas entre interesses públicos e privados (SADER, 2005). A política pública é comumente entendida como aquelas ações governamentais que influenciam a vida de um conjunto de cidadãos. Os autores aqui citados indicam que a tese tradicional da política tem como centro a máquina de estado, de onde emanariam projetos de governo e políticas públicas. A política estatal operada pela máquina estatal, segundo Passos e Barros (2009), funciona individualizando, segmentarizando e interiorizando. Tem como característica certa estabilidade, e funciona por meio da lei e da portaria. As políticas de governo são marcadas pela efemeridade dos grupos que ocupam um lugar na máquina de Estado. Seu funcionamento é descontínuo e volátil, e depende dos jogos de poder e dos interesses em cena. As políticas públicas são aquelas que estão conectadas com as forças do coletivo, com a experiência concreta dos humanos, e não de humanos idealizados e universalizados. Uma política estatal não necessariamente funciona como uma política pública, pois uma política pública opera fomentando a produção de diferenças, a singularização de modos de vida e não sua homogeneização. O que podemos perceber é que a política estatal tem seu funcionamento voltado à regulamentação dos modos de vida. Sendo nosso desafio interferir neste funcionamento de modo a tornar tais políticas públicas, ou seja, conectadas às demandas e proposições dos coletivos.

9 Podem ser citadas a Assistência Social, que instituiu conferências como parte de um sistema de participação institucionalizado (Lei n 9.720/1993), e a Conferência Nacional dos Direitos da Criança e do Adolescente, convocada bienalmente, desde 1995, pelo respectivo conselho nacional. (SOUZA,2012)

${ }^{10}$ O Centro de Referência da Juventude (CRJ) e o Núcleo Afro Odomode, são políticas de juventude do município de Vitória criadas no ano de 2006. O Centro de referência se propôs a ser um espaço de interação da juventude, que oferecia atividades de lazer, cultura, esporte, arte e música, além de dispor de estúdio aberto para ensaios de bandas. O Núcleo Afro desenvolve atividades culturais voltadas para jovens afrodescendentes, com oficinas e atividades que se propõem a contribuir com o resgate e a valorização da 
cultura afro, assim como sensibilizar os jovens para luta contra preconceitos e exclusões. Atualmente somente o Odomodê está em funcionamento, o CRJ está fechado e suas atividades estão se dando de forma itinerante no município.

${ }^{11}$ A Região Metropolitana da Grande Vitória contempla os municípios de Cariacica, Fundão, Guarapari, Serra, Viana, Vila Velha e Vitória. 